\title{
Comunicação
}

[Communication]

\section{Marcadores de proliferação celular na avaliação do crescimento do tumor sólido e ascítico de Ehrlich}

[Cell proliferation markers for evaluating the growth of solid and ascitic forms of Ehrlich tumor]

\author{
A.E. Silva, F.G.A. Santos, G.D. Cassali* \\ Instituto de Ciências Biológicas - UFMG \\ Caixa Postal 486 \\ 91270-901 - Belo Horizonte, MG
}

O tumor de Ehrlich é uma neoplasia experimental transplantável de origem epitelial maligna, espécie-específica e corresponde ao adenocarcinoma mamário do camundongo fêmea. Cresce em várias linhagens dessa espécie animal na forma ascítica, quando inoculado intraperitonealmente, e na forma sólida, quando inoculado no subcutâneo (Ehrlich, 1906). Tem sido utilizado no estudo da ação de componentes químicos, físicos e biológicos sobre o crescimento, patogênese, imunologia, citogenética e terapêutica de células tumorais (Segura et al., 2000; Mady, 2002; Palermo-Neto et al., 2003; Silva, 2003). A vantagem da utilização de neoplasias transplantáveis, em comparação às demais, recai sobre 0 conhecimento prévio da quantidade e das características iniciais das células tumorais a serem inoculadas e sobre o desenvolvimento rápido da neoplasia, que restringe o tempo de estudo (Stewart et al., 1959).

Uma das mais importantes características da transformação neoplásica é a perda do controle do ciclo celular, o que possibilita a expansão clonal (Ceccarelli et al., 2000). A determinação da taxa metabólica a partir da avaliação do índice mitótico, citometria de fluxo, marcadores imunoistoquímicos (Ki67, MIB e PCNA) e histoquímicos (AgNORs) tem sido amplamente utilizada, apresentando valor diagnóstico e prognóstico na patologia tumoral (Crocker et al., 1989; Pich et al., 2000).

$\mathrm{Na}$ rotina de trabalho com o tumor de Ehrlich, incluindo inoculação e manutenção do tumor, e na elaboração dos protocolos de pesquisa, é muito importante conhecer o seu comportamento e evolução nas diferentes formas. O objetivo deste trabalho foi avaliar a capacidade proliferativa das células do tumor de Ehrlich em dois microambientes: tecido subcutâneo (forma sólida) e peritôneo (forma ascítica), em diferentes períodos, a partir da utilização da imunoistoquímica (antígeno nuclear de proliferação celular - PCNA) e da técnica histoquímica de impregnação pela prata (AgNORs).

A citopatologia foi realizada em 10 camundongos BALB/c, machos, com três meses de idade, inoculados intraperitonialmente com $0,1 \mathrm{ml}$ da suspensão celular do tumor de Ehrlich $\left(5 \times 10^{6}\right.$ células), e a histopatologia com 10 camundongos $\mathrm{BALB} / \mathrm{c}$, machos, com três meses de idade, inoculados com $0,5 \mathrm{ml}\left(2,5 \times 10^{6}\right.$

Recebido em 6 de maio de 2004

Aceito em 2 de março de 2006

* Autor para correspondência (corresponding author)

E-mail: cassalig@mono.icb.ufmg.br 
células), no subcutâneo do coxim plantar. Para avaliação da curva de crescimento tumoral do Ehrlich sólido, foram feitas mensurações de espessura do coxim plantar, por meio de um micrômetro, imediatamente antes e após a inoculação, com intervalo de 24 horas. Os animais foram sacrificados em diferentes períodos pós-inoculação (7 e 14 dias). Nos inoculados intraperitonealmente, foram feitos esfregaços, confeccionados a partir da aspiração do líquido ascítico. Dos camundongos inoculados no subcutâneo, colheu-se o coxim plantar, e cortes de $4 \mu \mathrm{m}$ foram obtidos para análise histopatológica.

Nas lâminas citológicas e histológicas, foram realizadas análises imunoistoquímicas para detecção do PCNA, utilizando-se anticorpo monoclonal anti-PCNA, sendo a freqüência determinada pela porcentagem de células positivas em 1000 células tumorais. As lâminas também foram coradas pela técnica de AgNORs descrita por Ploton et al. (1986), com modificações propostas por Aubele et al. (1994). As AgNORs foram estudadas usando-se um analisador de imagens digital (Programa KS300; versão 2.0, da Kontron Elektronik) em que se avaliaram os seguintes parâmetros: número e área de AgNORs no núcleo e caracterização morfológica e distribuição dessas regiões. Cinqüenta núcleos por caso/lâmina foram analisados a um aumento de 100x.

À microscopia, o tumor sólido de Ehrlich apresentou células intensamente pleomórficas e anaplásicas, com relação núcleo-citoplasma elevada, núcleo com cromatina frouxa e nucléolos proeminentes. $O$ índice mitótico foi alto, com várias figuras de mitose atípicas. $\mathrm{O}$ estroma foi constituído por fibras colágenas e delicados capilares. Observaram-se extensas áreas de necrose e hemorragia. A taxa de crescimento neoplásico foi maior a partir de sete dias (Fig.1). A forma ascítica apresentou células levemente maiores do que a forma sólida, mas com referência a outros aspectos foi similar.

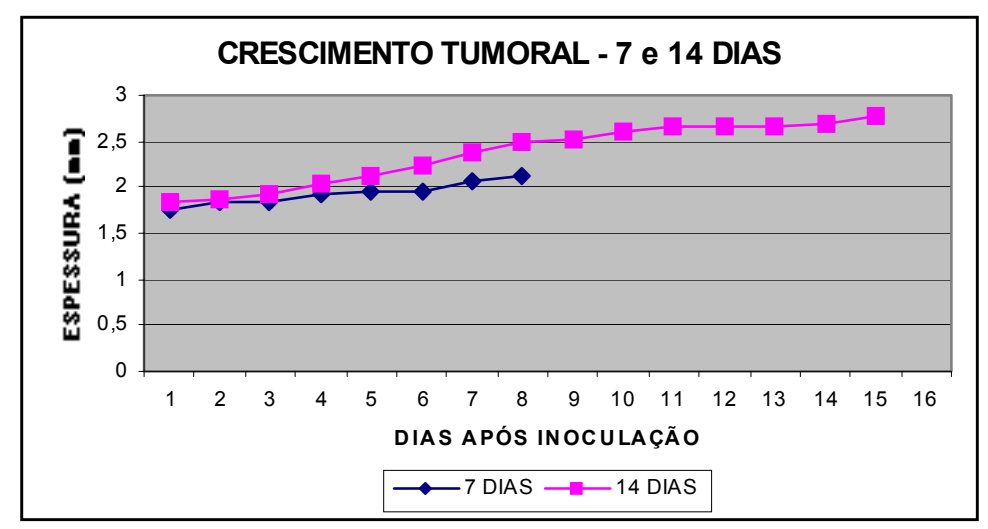

Figura 1. Curva de crescimento (mm) do tumor sólido de Ehrlich do dia 0 ao dia 14 em camundongos $\mathrm{BALB} / \mathrm{c}$.

Nas lâminas citológicas e histológicas, a imunomarcação pelo anti-PCNA foi nuclear, com padrão granular e intensidade variável. A porcentagem de células positivas foi significativamente maior no grupo de sete dias $(96 \%)$ em relação ao grupo de 14 dias $(86,4 \%)$. $\mathrm{Na}$ histologia observou-se o inverso, ou seja, o grupo de 14 dias $(76,4 \%)$ apresentou maior porcentagem de imunomarcadas para o PCNA em relação ao grupo de sete dias $(61 \%)$, fato que sinaliza para uma possível diferença na curva de crescimento entre o tumor sólido e ascítico.

No tumor ascítico, as NORs estavam fortemente unidas, constituindo estruturas argirofílicas grandes, arredondadas ou irregulares, preenchendo totalmente o nucléolo. Em alguns casos, pequenas NORs podiam ser vistas dispersas pelo núcleo. No tumor sólido, predominavam NORs variando de pequenas a 
médias, algumas isoladas, outras no centro do nucléolo, ou distribuídas sob o aspecto de cordão, formando um arranjo em colar ao redor do núcleo e nucléolo.

As análises morfométricas mostraram que o grupo de 14 dias apresentou número e área de AgNOR significativamente maiores em relação à histologia do grupo de sete dias (Fig. 2). Essas diferenças foram compatíveis com as avaliações macroscópicas do crescimento tumoral observadas nos dois grupos. Na citologia, nos mesmos tempos comparados, observou-se que as amostras do grupo de sete dias, tanto no número de AgNOR como na área, apresentaram-se significativamente maiores (Fig. 2). Essas alterações na atividade proliferativa, expressas pelos parâmetros das NORs, sugerem que o próprio ambiente intraperitoneal pode ter favorecido a maior velocidade de proliferação das células neoplásicas no período de sete dias, devido à presença de grande quantidade de nutrientes, espaço, ausência de tensões e condições propicias à multiplicação celular. No período de 14 dias, as células neoplásicas podem ter sido "desestimuladas" a entrarem em ciclo celular, possivelmente pela diminuição da oferta de nutrientes e maior quantidade de células neoplásicas. O método de AgNOR pode ter sido sensível e permitido identificação precoce das mudanças intranucleares (Ploton et al., 1986; Derenzine e Treré 1991).

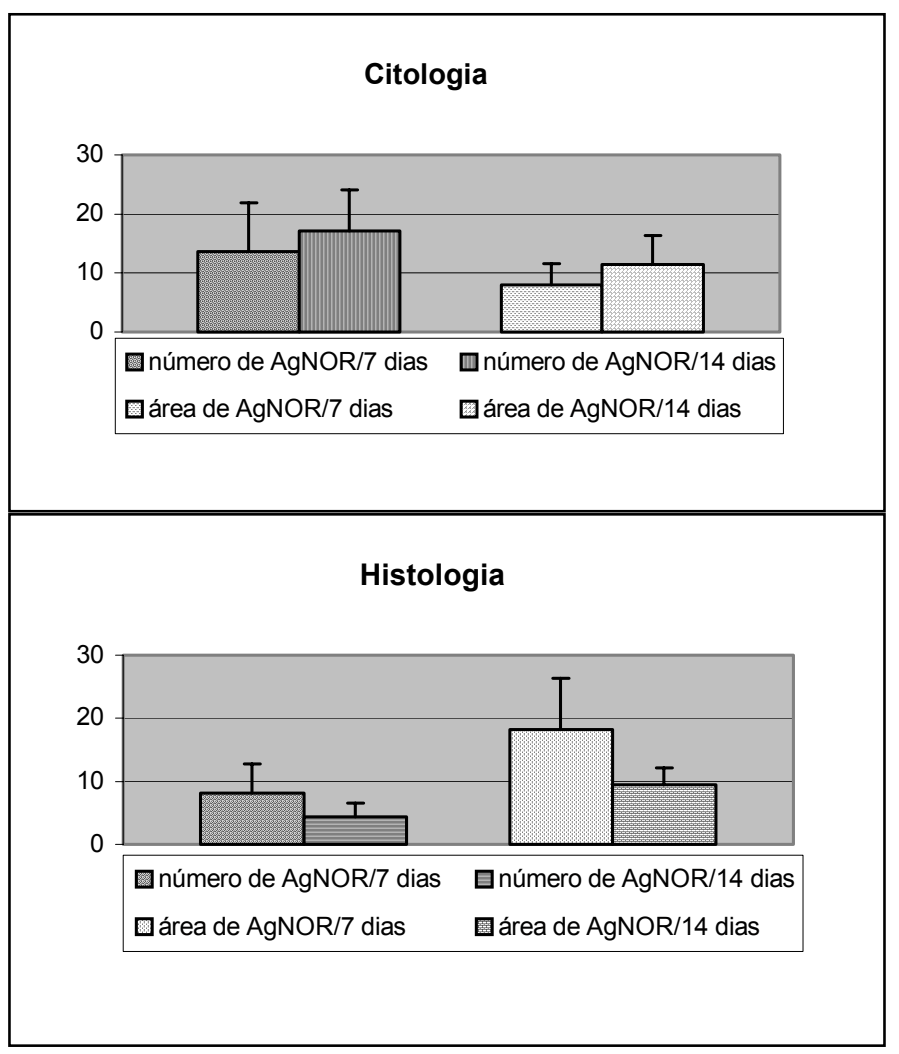

Figura 2. Número de AgNORs com 7 e 14 dias no tumor sólido e ascítico de Ehrlich em camundongos $\mathrm{BALB} / \mathrm{c}$.

Os resultados revelam, por ambas as técnicas, maior proliferação do tumor de Ehrlich na forma ascítica aos sete dias e na forma sólida aos 14 dias. Sendo o PCNA uma medida da fração de células em proliferação e os parâmetros de
AgNORs bons indicadores da velocidade de proliferação do ciclo celular, essas alterações na atividade proliferativa sugerem que a curva de crescimento das formas sólida e ascítica do tumor experimental de Ehrlich são diferentes. 
Enquanto na forma ascítica o pico de proliferação ocorre precocemente aos sete dias, no tumor sólido é mais tardio, tendo sua proliferação celular potencializada a partir do sétimo dia.
Palavras-chave: camundongo, tumor de Ehrlich, AgNOR, PCNA.

\begin{abstract}
Twenty BALB/c mice were inoculated with cell suspension of Ehrlich tumor. Ten mice were inoculated in the cushion plant (solid form) and the other 10 in the peritoneum (ascitic form). Animals were euthanized on different times ( 7 and 14 days). Cytological and histological slides, immunohistochemical (PCNA) analysis and NORs silver impregnation technique were performed. The results showed more proliferation on the $7^{\text {th }}$ day in the ascitic form and on $14^{\text {th }}$ day in the solid form, using both analyses (PCNA and AgNORs). The alterations observed in the Ehrlich tumor's proliferation activity suggested that the growth curve is different between ascitic and solid forms. In the first one, the proliferation peak occurs on the seventh day and in the solid tumor the growth curve was more delayed, showing increased proliferative potential after seven days.
\end{abstract}

Keywords: mice, Ehrlich tumor, AgNOR, PCNA.

\section{REFERÊNCIAS BIBLIOGRÁFICAS}

AUBELE, M.; BIESTERFELD, S.; DERENZINI, M. Guidelines of AgNOR quantitation. Zentralblatt für Pathol., v.140, p107-108, 1994.

CECCARELLI, C.; TRERÈ, D.; SANTINE, D. et al. AgNORs in breast tumours. Micron, v. 31, p. 143-149, 2000.

CROCKER, J.; BOLDY, D.A.R.; EGAN, M.J. How should we count AgNORs? Proposal for a standardized approach. J. Pathol., v.158, p.185188, 1989.

DERENZINE, M.; TRERÉ, D. Standartization of interphase AgNOR measurament by means of na automated image analisis system using lymphocytes as na internal control. J. Pathol., v.165, p.337-342, 1991.

EHRLICH, P. Experimentelle carcinomstudien an Mäusen. Arb. Inst. Exp. Ther. Frankfurt, v.1, p. 78-80, 1906.

MADY, E.A. Antitumor and biochemical effects of Echis coloratus Crude venon on Ehrlich ascite carcinoma cells in vivo. J. Venon Anim. Toxins, v.8, p.283-296, 2002.

PALERMO-NETO, J.; MASSOCO, C.O.; SOUZA, W.R. Effects of physical and psychological stressors on behaviour, macrophage activity, and Ehrlich tumor growth. Brain Behav. Immun., v.17, p. 43-54, 2003.

PICH, A.; CHIUSA, L.; MARGARIA, E. Prognostic relevance of AgNOR in tumor pathology. Micron, v.31, p.133-141, 2000.

PLOTON, D.; MENAGER, M.; JEANNESSON, P. improvement in the staining and the visualization of the argyrophlic proteins of nucleolar organizer regions at the optical level. Histochem. J., v.18, p.5-14, 1986.

SEGURA, J. A.; BARBERO, L.G.; MÁRQUEZ, J. Ehrlich ascites tumour unbalances splenic cell populations and reduces responsiveness of $\mathrm{T}$ cells to Staphylococcus aureus enterotoxin B stimulation. Immunol. Lett., v.74, p.111-115, 2000.

SILVA, A.E. Efeito do hipotireoidismo no tumor de Ehrlich na deficiência ou suficiência dos esteróides sexuais femininos, 2003. 85f. Dissertação (Mestrado em Patologia) - Escola de Veterinária, Universidade Federal de Minas Gerais, Belo Horizonte.

STEWART, H.L. (Ed.). Transplantable and transmissible tumors of animals. Washington, D.C.: Armed Fource Institute of Pathology, 1959. 378p. 